\title{
processo orçamentário e a apuração de custos de produtos e serviços no setor público do Brasil
}

Carlos A. Luque, Hélio N. Cruг, Cicely M. Amaral, Siegfried Bender e Paulo M. dos Santos

\section{Introdução}

O objetivo deste artigo é o de explicitar uma sistemática de análise e apuração de custos de serviços públicos que seja adaptada ao próprio processo orçamentário do setor público brasileiro e, assim, contribuir para a obtenção da eficiência alocativa e operacional. Uma característica fundamental dessa sistemática de apuração de custos é o fato de que ela é totalmente compatível e integrada com os sistemas gerenciais de informação utilizados pelo Governo. Outra característica consiste em seu baixo custo de operacionalização porque não implica mudanças apreciáveis nos sistemas de informação em uso e na forma atual de registro das informações na contabilidade pública.

O processo orçamentário tem sido objeto de reformulações importantes na busca da melhoria da gestão pública. Nos Estados Unidos, por exemplo, desde os anos 50 diversas iniciativas ${ }^{1}$ procuraram vincular a elaboração e execução do orçamento de modo crescente com o desempenho orçamentário efetivamente 
alcançado, como foi o caso do Planejamento-Programação-Sistema Orçamentário (PPBS), da Administração por Objetivos $(M B O)$ e da Orçamentação de Base Zero $(Z B B)$. Entretanto, como aponta Freitas (1999, p.101),

é consenso entre analistas que todos esses esforços, sejam de iniciativa do Executivo ou Legislativo, falharam em mudar o foco do processo orçamentário federal de sua tradição baseada em itens de despesa para resultados dos respectivos programas públicos.

Entre as razões para o fracasso em vincular a dotação no orçamento ao desempenho alcançado, Shick (1998) aponta para a existência de grupos de interesse organizados, pois impedem a realocação dessas verbas para as prioridades governamentais e para programas de interesse social atuais. Esse tipo de ação dos grupos de interesse leva à perpetuação da prática do incrementalismo e da inércia na elaboração orçamentária. Outra razão para o possível fracasso das iniciativas de reformulação de orçamento, segundo Rezende ${ }^{2}$, pode ser uma forte vigilância do Legislativo sobre a execução orçamentária. Nesse caso, Schick também registra que ocorre a indução de uma ação na administração pública pautada pela estrita obediência ao que tradicionalmente se aceita como boa regra de gestão orçamentária. Esta prioriza a gestão financeiro-orçamentária seguindo regras historicamente estabelecidas, em detrimento de questões como boa performance da política fiscal e da obtenção de resultados efetivos na sociedade, ou ainda de qualidade e de flexibilização e responsabilização na gestão pública.

Do ponto de vista conceitual, instituição orçamentária é o conjunto de regras e procedimentos pelos quais os orçamentos são escritos, modificados, aprovados pelo Congresso e executados ${ }^{3}$. Como aponta Schick (1998), os princípios básicos do orçamento público têm sido elaborados e refinados ao longo do tempo e mantido considerável estabilidade. Princípios e procedimentos acumulados constituem a estrutura legal do processo orçamentário. São implementados mediante regras processuais detalhadas que, por exemplo, especificam o escopo do orçamento, a informação a ser incluída, a periodização no tempo para tomar certas ações, as formas a serem utilizadas, as autorizações requeridas antes que certos fundos públicos sejam alocados e gastos, e assim por diante. Cada um dos princípios orçamentários é suportado por regras formais impostas por controladores de orçamento posicionados em diversos níveis das esferas do setor público.

$\mathrm{Na}$ ótica tradicional do processo orçamentário, se o orçamento é abrangente e todos os pedidos por recursos são submetidos e revistos de acordo com a programação, então as alocações efetuadas aos departamentos e programas tendem a ser aceitas como legítimas e eficientes. Não há o confronto entre a elaboração orçamentária, a execução orçamentária e os resultados efetivos induzidos na economia e na sociedade pela política fiscal implícita no processo orçamentário. Em suma, a avaliação tradicional do processo orçamentário segue critérios não substantivos e parece partir do princípio de que é uma atividade autocontida, com seus próprios rituais, regras e papéis, sendo indiferente à natureza dos resultados fiscais efetivamente alcançados na sociedade.

Nos anos 70 observou-se considerável deterioração no desempenho fiscal dos países desenvolvidos, com a generalização 
de déficits públicos elevados, endividamento público e inflação crescente. Esse estado de coisas suscitou o questionamento: como resultados fiscais adversos podem decorrer de procedimentos orçamentários tidos como robustos pelos parâmetros tradicionais? O diagnóstico sobre a sistemática do processo orçamentário em vigor, bem como sobre as causas do insucesso das iniciativas de reformulação do processo orçamentário, como as mencionadas acima, detectou alguns problemas recorrentes. Em primeiro lugar, concluiu-se que os governos são constantemente pressionados a gastar mais do que sua base econômica tributária pode sustentar. O principal mecanismo indutor desse viés gastador é a natureza intrínseca colegiada e descentralizada que existe no processo orçamentário e que leva ao chamado "problema do uso de recursos comuns" ou "tragédia dos comuns" (Velasco, 1998). Outra disfunção comum detectada é a forte inércia orçamentária, a qual resulta da prática do incrementalismo orçamentário e é sustentada pelos grupos de interesse. A inércia orçamentária se manifesta na tendência de continuar financiando programas antigos e disfuncionais, mesmo que novas prioridades sejam mais urgentes, bem como o dispêndio crescente em departamentos e agências altamente ineficientes.

Portanto, uma nova reformulação ampla dos sistemas orçamentários vigentes que pretenda a correção dos problemas diagnosticados deveria, em princípio, buscar soluções novas e criativas para resolver as questões seguintes: induzir a disciplina fiscal agregada; capacitar o Governo a alocar os recursos segundo as prioridades estratégicas e os objetivos sociais vigentes, isto é, buscar a eficiência alocativa no dispêndio público; e encorajar a eficiência operacional na execução orçamentária, ou seja, induzir à obtenção dos produtos/serviços governamentais desejados ao menor custo possível. Nesse sentido, o padrão de análise de processos orçamentários introduzido por Campos e Pradham (1996), o qual adota uma perspectiva de cunho institucional no diagnóstico e na proposição de soluções para os três grandes objetivos do processo orçamentário (disciplina fiscal agregada, eficiência alocativa e eficiência operacional),

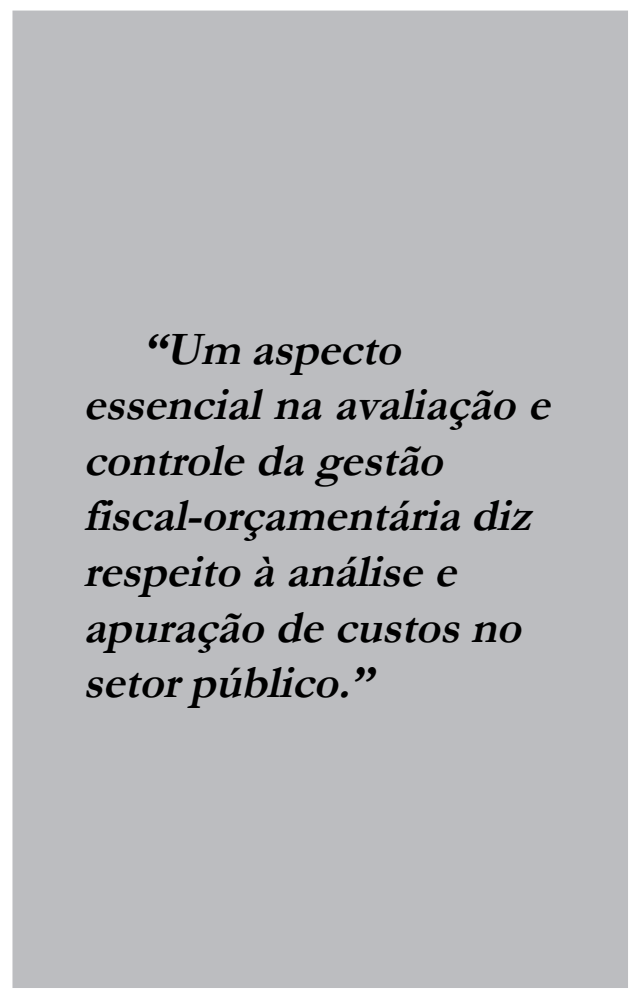

tornou-se a métrica atual. Segundo essa métrica é que os sistemas orçamentários são analisados, comparados, e as propostas de reformulação do processo orçamentário são organizadas. Essa visão também está presente na recente onda de reformulações do processo orçamentário, iniciada ao longo dos anos 80, e que tem sido denominada de nova administração do dispêndio público ${ }^{4}$. 
O ímpeto renovador que se verifica nos processos orçamentários em diversos países desenvolvidos ${ }^{5}$ também tem reflexos no Brasil, onde ocorreram mudanças orçamentário-institucionais com o propósito principal de propiciar um regime fiscal condizente com a estabilidade econômica. Embora no caso brasileiro não haja uma reformulação ampla, profunda e concatenada do processo orçamentário, como preconizado pela nova administração do dispêndio público, as mudanças institucionais aqui introduzidas constituemse de alguns elementos articulados do que seria essa reformulação. $O$ sentido geral das mudanças efetuadas é o de fomentar a responsabilidade fiscal agregada e o de pressionar por uma vinculação do processo orçamentário com os resultados alcançados, isto é, com o grau de cumprimento das metas de produção pública e com a correspondente avaliação do desempenho alcançado. As mudanças também pretendem introduzir maior flexibilidade na administração pública, mas, evidentemente, acompanhada de responsabilização. Garces e Silveira (2002) analisam um conjunto de medidas em nível federal que comungam dessa nova perspectiva no Brasil. Assim, a partir de 1998 foram inseridas mudanças institucionais mediante três instrumentos legais que modificaram significativamente a gestão pública: a Lei do PPA 2000-2003, o Decreto Lei $n^{\circ}$ 2.829, de 29 de outubro de 1998, e a Lei de Responsabilidade Fiscal ${ }^{6}$ promulgada em 4 de maio de 2000.

A Lei do PPA 2000-2003 e o Decreto $\mathrm{n}^{\circ} 2.829$, de 1998, estabelecem a avaliação de desempenho como uma das etapas mais importantes do ciclo de gestão do Governo. A metodologia para essa avaliação valoriza principalmente a análise de resultados, mostrada tanto pela variação de indicadores associados aos programas quanto pelo grau de satisfação alcançado junto ao públicoalvo. As considerações de mensuração de resultados por indicadores pertinentes e do grau de satisfação do público com os serviços governamentais também se constituem em pedras angulares nas reformulações do processo orçamentário, sob a ótica da nova administração do dispêndio público. Já o Decreto n 2.829, de 1998, na busca de maior flexibilidade na administração pública federal no Brasil, cria, entre outras determinações, a figura do gerente de programa, fixando suas principais responsabilidades e exigindo a avaliação anual de desempenho de todos os programas e do plano. Ou seja, no dizer de Garces e Silveira (2002), observa-se aqui o princípio da responsabilização clara pelo desempenho, custos e resultados. Mas o principal instrumento de flexibilização na administração pública, na nova postura da gestão pública no País, constitui-se dos contratos de gestão, como aponta Catelli et alli $(2001)^{7}$. Esses instrumentos expressam o relacionamento agente-principal entre o Governo e organizações e entidades, tais como as agências reguladoras, as quais têm autonomia gerencial, com controle de resultados, e cujo contrato de gestão estabelece certos objetivos a serem alcançados em determinado período.

Outro instrumento de inovação da gestão fiscal no Brasil é a Lei de Responsabilidade Fiscal (LRF) - uma lei abrangente, pois contempla muitos aspectos das finanças públicas e, por isso, complexa que, sem dúvida, constitui-se hoje no instrumento fiscal mais importante. Após um longo processo de desequilíbrio fiscal e instabilidade inflacionária na economia brasileira, a LRF expressa um aprendizado sobre como orientar as instituições nas questões orçamentárias e na gestão fiscal 
do País, de forma que seja favorecido, em todos os entes da Federação, um regime fiscal compatível com a estabilidade da economia. No que tange a gastos públicos, por exemplo, a LRF estabelece limites rígidos e bem elaborados para os gastos de pessoal e para o endividamento público, define mecanismos de correção de desvios e as sanções para o caso de descumprimento das normas legais, bem como fecha vários subterfúgios que, eventualmente, possam ser utilizados para burlar o espírito da lei. Note-se também que o estabelecimento de limites aos gastos e ao endividamento público tem pleno respaldo na literatura de economia política. Tabellini e Alesina (1990) mostram que limites ao gasto e ao déficit têm eficácia e afetam o resultado fiscal. Assim, ao limitar gastos e endividamento público e ao proibir o aumento da despesa de pessoal a seis meses do término do mandato, a LRF busca eliminar tanto o comportamento estratégico dos governantes quanto o ciclo político dos gastos e das receitas públicas, induzindo à disciplina fiscal agregada (intertemporal) no regime fiscal do País.

Entretanto, ressalta Giuberti (2005), a LRF não se restringe a impor limites ao gasto e ao endividamento; contempla também o orçamento como um todo, ao estabelecer diretrizes para sua elaboração, execução e avaliação. Assim, no que tange ao processo orçamentário propriamente dito, a LRF aprofunda a integração entre planejamento, orçamento e execução fiscal concebida pela Constituição Federal de 1988 para a União e, o que constitui uma grande mudança institucional orçamentária, também impõe essa ótica do processo orçamentário para os estados, o Distrito Federal e os municípios - que, por falta de lei complementar da Constituição de 1988 até a promulgação da LRF, em nível federal continuavam regidos no processo orçamentário pela Lei Federal 4.320/64. No Capítulo II, Seção II, a Constituição de 1988 normatiza o processo orçamentário da União mediante três leis orçamentárias funcionalmente integradas: a Lei do Plano Plurianual (PPA), a Lei de Diretrizes Orçamentárias (LDO) e a Lei do Orçamento Anual (LOA). A LRF estabelece que essa sistemática do processo orçamentário federal se estenda para os outros níveis da Federação e introduz algumas alterações às leis orçamentárias. Com relação à LDO, a LRF estabeleceu o Anexo de Metas Fiscais para três anos, contendo metas para receita, despesa, resultado primário e nominal, dívida pública e medidas que permitem uma avaliação do cumprimento das metas. Introduziu também o Anexo de Riscos Fiscais com identificação dos passivos contingentes e de outros riscos na gestão pública.

Com relação à LOA, a LRF impôs a elaboração de um Demonstrativo de Compatibilidade do Orçamento no Anexo de Metas Fiscais e a obrigação da publicação semestral do Relatório Resumido de Execução Orçamentária. Assim, como conclui Giuberti, as medidas da LRF trazem maior transparência ao processo de elaboração e execução do orçamento e visam a garantir a consistência entre objetivos e metas (expressos no PPA e LDO) com a execução fiscal (via LOA). Para Nascimento (2004), a LRF institucionalizou o regime de metas fiscais, fazendo com que o orçamento seja elaborado para cumprir as metas físicas do PPA e as metas fiscais da LDO.

A despeito das profundas e amplas alterações introduzidas pela LRF no processo orçamentário e na gestão fiscal brasileira, essa lei não normatiza um aspecto essencial relativo à avaliação e controle da 
gestão pública, que é a análise e apuração de custos no setor público. Shick (1998) lembra um fato crucial ao comentar sobre um tipo de reformas recentes do processo orçamentário em países não desenvolvidos que adotam elementos da ótica da nova administração do dispêndio público e, assim, buscam se distanciar de controles centralizados do orçamento ao ampliar a flexibilidade operacional a administradores públicos. Esse analista alerta que os países desenvolvidos, líderes das novas reformas orçamentárias (Nova Zelândia, Austrália, Inglaterra e Suécia), somente deram maior liberdade orçamentária aos administradores públicos após terem sido estabelecidos sistemas de controle confiáveis. Entre os controles imprescindíveis está, obviamente, um adequado sistema geral de análise e apuração de custos.

Assim sendo, um aspecto essencial na avaliação e controle da gestão fiscalorçamentária diz respeito à análise e apuração de custos no setor público. Um sistema de análise e apuração de custos é imprescindível para possibilitar tanto a eficiência operacional quanto a eficiência alocativa no processo orçamentário. Pela reflexão de Shick sobre reformas orçamentárias recentes em países menos desenvolvidos, um sistema de controle de custos seria também uma condição necessária para que as reformas do processo orçamentário, na ótica da nova administração do dispêndio público, sejam bemsucedidas.

Entretanto, mesmo sendo esse instrumento um elemento essencial de gestão orçamentário-fiscal, necessita ainda de uma formulação adequada para o setor público brasileiro. Essa situação também não é melhorada pela LRF, pois no aspecto relativo à análise e apuração de custos essa lei é bastante sucinta. A LRF menciona esse assunto de forma genérica tanto na alínea (e) do Artigo $4^{\circ}$, em que se explicita que a "LDO conterá normas relativas ao controle de custos e à avaliação dos resultados dos programas financiados com recursos dos orçamentos", quanto no Parágrafo $3^{\circ}$ do Artigo 50, no qual diz que "a administração pública manterá sistema de custos que permita a avaliação e o acompanhamento da gestão orçamentária, financeira e patrimonial". Ou seja, a menção que a LRF faz a esse aspecto central de análise e apuração de custos no setor público é genérica e não especifica qualquer detalhe relacionado à sua operacionalização - ao contrário do que faz, por exemplo, quando trata da questão dos gastos e do endividamento públicos, ou da elaboração, execução, avaliação e controle do processo orçamentário. Evidentemente, isso não significa que haja uma desconsideração sobre a importância da análise e apuração de custos, sem dúvida essencial para obtenção da eficiência operacional e alocativa no processo orçamentário; mas reflete o fato de que a análise e apuração de custos por um sistema geral de custos no setor público não teve até hoje uma solução razoável ${ }^{8}$.

Constitui objetivo maior deste artigo a explicitação de uma nova sistemática de apuração de custos de produtos/serviços e atividades no setor público brasileiro, sendo essa sistemática totalmente compatível e integrada com os sistemas gerenciais de informação em uso no Governo. O sistema de apuração de custos é relativamente abrangente e preciso, sendo exeqüível e de baixo custo de operacionalização, pois não implica mudanças apreciáveis nos atuais sistemas de informação nem na forma de registro das informações na contabilidade pública. Nesse aspecto, o presente artigo busca 
complementar a LRF, no que se refere à análise e apuração de custos, com um sistema geral de custos adequado ao setor público e seus sistemas de informação, como também busca viabilizar a obtenção de maior eficiência operacional e alocativa no processo orçamentário. $\mathrm{O}$ artigo segue no item (II) com a análise de algumas abordagens da literatura de custos para o setor público brasileiro; no item (III), identifica os custos nesse setor; no item (IV), explicita o sistema de apuração de custos; e no item (V), faz as considerações finais.

\section{Considerações da literatura de custos aplicada ao setor público do Brasil}

Entre os estudos sobre apuração de custos de serviços públicos no Brasil, a análise de Machado (2000) tem posição de destaque. Ao analisar um sistema de custos apropriado ao setor público, Machado defende a adoção do custeio direto na apuração, entre os cinco métodos de custeio ou apropriação de custos ${ }^{9}$. A justificativa para essa escolha é a de que tal método permite analisar o desempenho dos gestores e das políticas públicas com maior objetividade, por não conter qualquer tipo de rateio. Ou seja, em termos dos três principais objetivos que deveriam ser atendidos por um processo orçamentário - disciplina fiscal agregada, eficiência alocativa e eficiência operacional Machado implicitamente justifica a opção pelo método de custeio direto porque este contribui para administrar a ação no setor público em direção à eficiência operacional no processo orçamentário. O maior problema nessa escolha está, todavia, no fato de que os custos indiretos são, cada vez mais, muito importantes no setor público. E, por isso, o custeio direto subestima significativamente os custos incorridos nas diversas atividades e produtos/serviços desenvolvidos pelo Governo. Essa subestimação de custos, por sua vez, distorce qualquer análise de custobenefício de determinado produto/ serviço e atividade do setor público. Desse modo, com o custeio direto torna-se difícil o cumprimento de outro objetivo muito importante no processo orçamentário: o

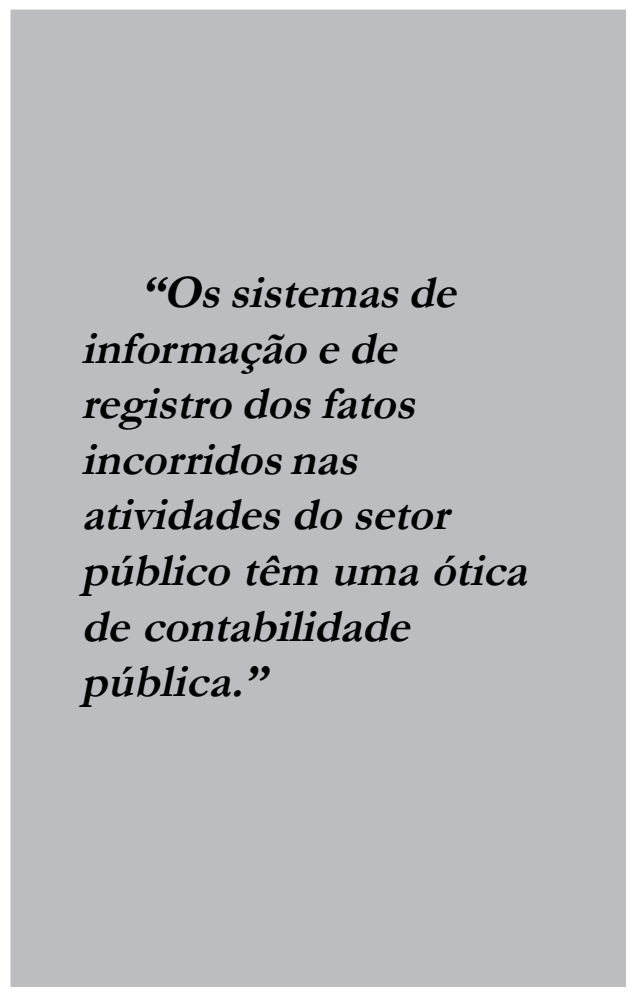

de obtenção da eficiência alocativa do dispêndio público.

Além disso, outro problema importante na abordagem de custo direto se refere à complexidade envolvida no levantamento dos custos fixos de capital (diretos ou indiretos). Assim, a própria apuração dos custos diretos de determinado produto/serviço ou atividade é ambígua, pois, em tese, deve incluir todos 
os custos fixos diretos. Portanto, nos casos de produtos/serviços ou atividades em que os custos fixos diretos de capital são importantes, resulta que o próprio levantamento do custo direto é impreciso. Nesse caso não haveria, na verdade, a alegada objetividade na análise do desempenho dos gestores e das políticas públicas. Dito de outra forma, caso a imprecisão no custo direto seja expressiva, então não está nem garantido que o custeio direto leve à eficiência operacional no processo orçamentário.

Uma segunda linha de análise é seguida por Catelli et alli (2001). Seu objetivo é expor conceitos, critérios e instrumentos que possibilitam a gestão econômica das organizações públicas como criadoras de valor, sendo esses desenvolvidos pelo Sistema de Gestão Econômica (CATElli, 1999). Nesse intuito, a análise de Catelli et alli se contrapõe à avaliação das atividades governamentais apenas por índices físicos quantitativos, pois busca balizar essa avaliação em termos de benefícios monetários em relação aos custos incorridos e, assim, torna a "abordagem contábilgerencial do 'governo por resultados' uma abordagem da gestão pública como criadora de valor" (CATELl et alli, 2001, p.84).

$\mathrm{Na}$ abordagem de gestão econômica das organizações públicas há dois problemas a serem resolvidos para a apuração do resultado econômico: a mensuração do valor e a mensuração dos custos na atividade pública. Em primeiro lugar, no que diz respeito à identificação do valor criado pela atividade pública, essa abordagem faz uso do conceito de custo de oportunidade. Todavia, a operacionalização do custo de oportunidade que se adota é pragmática, embora conceitualmente não rigorosa. Identifica-se o custo de oportunidade de uma atividade pública como o valor da melhor alternativa disponível na sociedade para a obtenção desse serviço. Por exemplo, o custo de oportunidade dos serviços ambulatoriais fornecidos pelo Estado, nessa interpretação, seriam os menores custos (preço) dos serviços ambulatoriais na rede privada. Evidentemente, isso somente tem aplicação para serviços governamentais que também tenham produção privada.

Por outro lado, no que diz respeito à mensuração de custos incorridos em determinada atividade do setor público,

a gestão econômica adota o método de custeio direto, considerando que o uso de rateio, embora freqüente, não se presta à identificação do valor criado em cada decisão, uma vez que apenas atribui um valor médio obtido por divisão matemática, sem se preocupar com o efetivo relacionamento entre os custos e as suas causas (CATELLI et alli, 2001, p.92).

Assim, ao utilizar o custeio direto no cálculo do resultado econômico, o que de fato se obtém é a mensuração da margem de contribuição de determinado produto/ serviço governamental.

Portanto, especificamente no que diz respeito ao levantamento de custos, a adoção do custeio direto por essa abordagem mostra que ela incorre, pelo menos, nos mesmos problemas que foram explicitados anteriormente para a abordagem de Machado. Ou seja, somente no caso em que a imprecisão no levantamento dos custos diretos não seja expressiva, a abordagem de gestão econômica das organizações públicas contribui, em tese, para a obtenção da eficiência operacional, mas não contribui para a obtenção da eficiência alocativa do dispêndio público 
no processo orçamentário. Além disso, a abordagem de gestão econômica compartilha, com a proposta de Machado, da ambigüidade que existe na própria mensuração do custo direto, o que ocorre quando os custos fixos (diretos) de capital são importantes. Mas há, ainda, uma restrição adicional muito importante nessa abordagem, pois ela somente pode ser aplicada nas situações em que o produto/serviço público tenha correspondente produção privada, o que, sabidamente, é apenas uma parcela restrita do conjunto de atividades e de produtos/serviços desenvolvidos pelo setor público.

Uma terceira linha de análise, com relação à apuração de custos no setor público, é explicitada em Alonso (1999). Parte do pressuposto de que a metodologia tradicional de custeio, frente às novas condições de produção ${ }^{10}$, apresenta limitações que levam a "profundas distorções na apuração do custo de produtos e dos processos de trabalho" (Alonso 1999, p.42). Disso resultou a busca de novas metodologias de custeio, as quais deram origem ao custeio baseado em atividades (ABC). Alonso argumenta que não há cultura de custos no serviço público brasileiro, apesar de saber que o conhecimento do custo dos serviços públicos é fundamental para se atingir uma alocação eficiente de recursos. A conseqüência disso, nota Alonso, é que

com os sistemas de informação existentes, incluído o Siafi, o Governo não sabe em que medida cada tipo de despesa contribui para os resultados obtidos. Mais ainda, ele não sabe quais atividades agregam valor ao resultado final das ações de governo. Também ignora qual é a taxa de consumo de recursos pelas atividades e quanto custam os processos de trabalho ou os programas governamentais. O governo desconhece, em resumo, onde há desperdício e onde há eficiência na aplicação dos recursos. De fato, o modelo de gestão tradicional do setor público prioriza o controle dos recursos e dos procedimentos formais, e não os resultados, o desempenho, a eficiência (Alonso, 1999, p. 39).

Portanto, na argumentação de Alonso há duas causas que fundamentam a inexistência de sistemática de análise e apuração de custos no setor público. A primeira resulta "da histórica falta de motivação para a apuração de custos no serviço público" (Alonso, 1999, p. 45), que, como ressaltamos anteriormente na Nota 8 , fundamentalmente reside no fato de que a rentabilidade, ou maximização de lucros, não é o critério relevante. A segunda consiste da "inadequação dos métodos de custeio tradicional às características do serviço público" (Alonso, 1999, p.45). Essa inadequação, segundo Alonso, reside no fato de que "no custeio tradicional o custo é determinado pelos centros de custo e critérios de rateio" (Alonso, 1999, p.45). Assim, a eventual escolha inadequada dos centros de custo, as mudanças freqüentes de estrutura dos órgãos e entidades governamentais e o elevado peso dos custos fixos e custos indiretos no setor público, que problematizam a escolha de critérios de rateio, fundamentam a alegada inadequação do custeio tradicional. Assim sendo, conclui Alonso, “...sustentamos a tese de que a administração pública deve ser dotada de sistemas de custo $\mathrm{ABC}$ e não de sistemas de custo tradicionais" (Alonso, 1999, p.45).

Entretanto, a despeito de algumas qualidades que o custeio ABC apresenta, cumpre aqui registrar a presença de 
problemas importantes que, na verdade, limitam muito sua aplicação ao setor público, como um sistema geral de análise e apuração de custos. Em primeiro lugar, esse método de custeio incorre em elevado custo de implantação, pois para cada produto/serviço ou atividade é necessário mapear o processo em foco e determinar todas as atividades direta e indiretamente envolvidas. Assim, mediante o uso de direcionadores de custo, o custeio $\mathrm{ABC}$ identificaria e atribuiria os custos diretos e ratearia (mas de modo objetivo) os custos indiretos envolvidos em cada um dos produtos/serviços e atividades. E, como se sabe, o número de produtos/serviços e atividades desenvolvidas no setor público é enorme, o que geraria excessivo custo de implantação desse sistema na perspectiva de um sistema geral de apuração rotineira de custos públicos. Em segundo lugar, como lembrou Alonso, no setor público ocorrem freqüentes mudanças na estrutura dos órgãos e entidades governamentais, bem como na composição de pessoal. Além disso, há a introdução constante de novas atividades e de produtos/serviços públicos. Assim sendo, toda vez que há essas mudanças, ocorre a necessidade de efetuar ajustes de maior ou menor grau no custeio ABC de todos os processos/ produtos/serviços e atividades direta e indiretamente envolvidos, o que novamente envolve custos significativos. Em terceiro lugar, um sistema de custos $A B C$, pela sua própria natureza, não seria funcionalmente integrado aos sistemas de informação existentes, mas envolveria a montagem de um sistema paralelo de informações e, portanto, seria custoso ao setor público e com limitações para a análise gerencial, orçamentária e financeira. Se todos os métodos de custeio pudessem informar com igual rapidez e sem custo de levantamento de informações sobre o andamento dos custos dos produtos/ serviços e atividades, de modo que decisões gerenciais pudessem ser tomadas com a oportunidade devida, o método de custeio mais preciso seria a escolha natural. No entanto, na prática, dados os sistemas de informação existentes, há uma enorme diferença entre os métodos de custeio quanto à rapidez com que podem informar sobre andamento dos custos. Os distintos métodos de custeio implicam uma expressiva diferença em termos de custo incorrido no levantamento das informações pertinentes (i.e., sobre os custos dos produtos e atividades) para a tomada de decisões. A preferência por algum método de custeio no setor público sempre envolve, além do necessário atendimento dos critérios de eficiência operacional e eficiência alocativa no processo orçamentário, considerações sobre balanceamento entre questões de rapidez, de fidedignidade e de custo de levantamento das informações, em contraposição à precisão das informações sobre os custos dos produtos e de atividades no Governo. Vimos antes que as propostas da literatura para sistemas de custo nesse setor nem sempre atendem aos dois requisitos imprescindíveis em relação ao processo orçamentário. Por exemplo, no caso do custeio direto, esse somente atende ao critério de eficiência operacional se os custos fixos de capital não forem importantes, mas não atende ao critério de eficiência alocativa. Já no caso do custeio por atividade, o problema está em que sua implantação é muito onerosa ao setor, não é integrado aos sistemas de informação existentes e prescinde de flexibilidade e adaptabilidade dinâmica que todo bom sistema geral de custos deve ter. 
Em suma, um sistema de custos baseado no método de custeio direto é claramente insuficiente no que diz respeito à capacidade de obtenção de eficiência operacional e eficiência alocativa no processo orçamentário. Por outro lado, o método de custeio por atividade $(\mathrm{ABC})$ é de difícil e custosa implantação e operacionalização, prescinde de adequada flexibilidade e adaptabilidade dinâmica, além de não ser funcionalmente integrado aos sistemas de informação existentes. Portanto, permanece em aberto a questão crucial sobre como se constituir um sistema geral de análise e apuração (rotineira) de custos para o setor público que sobrepuje as limitações apontadas.

\section{Identificação dos custos no setor público}

A noção econômica de custo está associada a produto ou serviço. Nessa perspectiva, os custos resultam da utilização de serviços de fatores de produção (capital e trabalho) e do consumo de recursos materiais (bens e serviços intermediários e matérias-primas) nas atividades direta e indiretamente envolvidas com a colocação de determinado produto ou serviço no mercado. Assim sendo, o custo total incorrido na colocação de determinado produto ou serviço no mercado constitui-se da soma das remunerações comprometidas com a utilização dos serviços do fator capital, com a utilização dos serviços do fator trabalho e com os gastos pela utilização ("consumo") de insumos intermediários, sendo os gastos com fatores, recursos materiais, bens e serviços intermediários vinculados diretamente à produção ou a atividades complementares.

Entretanto, os sistemas de informação e de registro dos fatos incorridos nas atividades do setor público têm uma ótica de contabilidade pública. Do ponto de vista contábil, as classificações utilizadas para custos atendem muitas vezes a objetivos distintos do enfoque puramente econômico, mas evidentemente deve haver sempre uma compatibilidade entre eles. $\mathrm{Na}$ construção de um sistema geral de custos deveremos, portanto, do ponto de vista contábil, concentrar-nos em conceitos que, além de abrangerem o custo total de

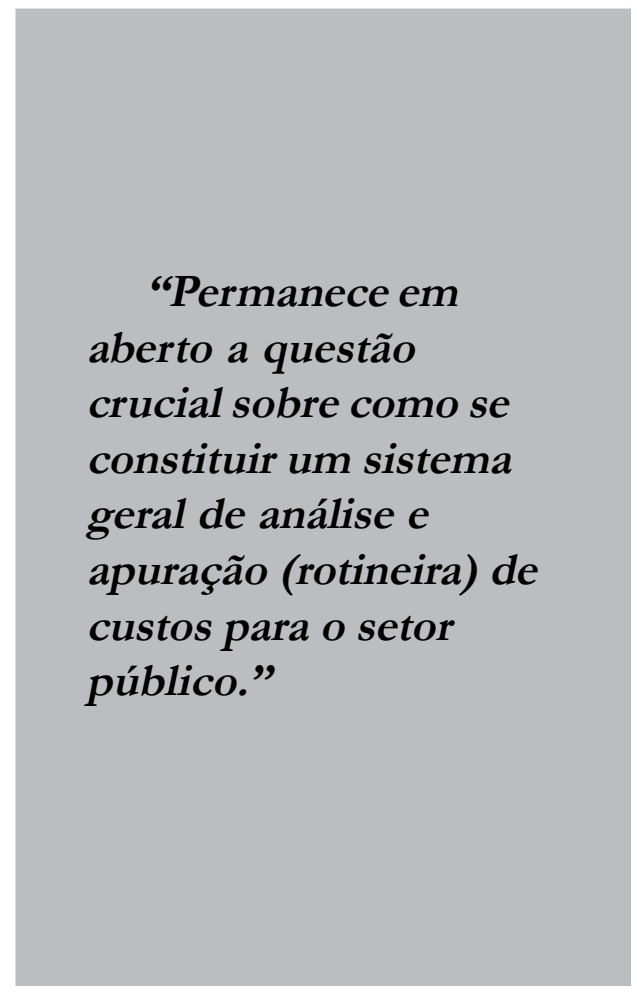

determinado produto ou serviço, sejam fáceis de elaborar, interpretar e compatibilizar com a noção econômica de custo. O mais apropriado parece ser a utilização dos conceitos tradicionais de custos: como de custos fixos e custos variáveis e de custos diretos e indiretos, sendo o custo total a soma do custo variável total (direto e indireto) com o custo fixo total (direto e indireto). Ou seja, tanto o custo variável 
quanto o custo fixo podem ser incluídos diretamente na produção ou em atividades complementares. Igualmente, seguiremos a abordagem tradicional que classifica como custos fixos as despesas com a utilização dos serviços do fator capital, e como custos variáveis as despesas com a utilização dos serviços do fator trabalho ${ }^{11}$ e com os gastos devidos ao consumo de insumos intermediários, tanto na atividade produtiva quanto em atividades complementares.

Em suma, do ponto de vista contábil, a categorização de custos que utilizaremos será a de custos fixos e custos variáveis, sendo cada um decomposto em custos diretos e custos indiretos vinculados a uma determinada atividade. Essa categorização contábil tem correspondência na categorização econômica da seguinte forma: os custos variáveis (diretos e indiretos) constituem-se das despesas com a utilização dos serviços do fator trabalho e dos gastos com o consumo de insumos intermediários nas atividades do setor público $^{12}$. Os custos fixos (diretos e indiretos) constituem-se das despesas com a utilização dos serviços do fator capital ${ }^{13}$ nas atividades do setor. Essas categorias se constituirão na referência básica de custos que adotaremos e elas permitirão constituir um sistema geral de custos.

Portanto, no cômputo dos custos "variáveis" dois tipos de despesas devem ser apurados pelo sistema de custos: as despesas com a utilização do fator trabalho, isto é, o custo de pessoal e os gastos com o consumo de materiais, bens e serviços intermediários nas atividades em determinado período de tempo. Com relação aos custos de pessoal, serão considerados todos os dispêndios de pessoal na ativa e desconsideradas todas as despesas com aposentadoria e outros benefícios previdenciários. Com relação aos gastos com materiais, bens e serviços intermediários, para efeitos de custo deverão ser considerados todos os valores das compras desses itens que resultaram em consumo em dado período.

Por outro lado, com relação à apuração dos custos de capital, ocorre um caso bastante diferenciado. $\mathrm{Na}$ prática, as limitações existentes à mensuração do custo de capital tornam difícil e ambígua a apuração rotineira do custo direto de produtos/serviços e atividades do Governo e impraticável a apuração do custo total. Tendo em vista os sistemas de informação do setor público, é preciso distinguir os dispêndios de capital em geral de gastos que se constituem em custo de capital (ver Nota 13). Na contabilidade pública, a Lei 4.320/64 separa esses dois tipos de gasto público em despesas correntes e despesas de capital ${ }^{14}$. Nos dispêndios de capital em geral, ou despesas de capital, temos inclusos os gastos com investimento público, tais como a construção de escolas, hospitais, rodovias etc. Nesse tipo de gasto de capital, isto é, de investimento público, incorrem-se em gastos com a utilização de serviços de fatores (trabalho e capital) e gastos com insumos intermediários para sua realização. Portanto, o investimento público é um tipo de produto gerado pelo setor público e que, em princípio, pode ser avaliado do ponto de vista de apuração de custos segundo a metodologia que sugerimos neste trabalho.

Já com relação aos dispêndios públicos que se constituem custo de capital, esses correspondem aos gastos pela utilização dos serviços do fator capital nas diversas atividades e estão contabilizados nas despesas correntes. Esses gastos, que são componentes do custo de capital, deveriam 
ser considerados em qualquer apuração de custos que se queira fazer com relação a atividades desenvolvidas pelo Governo. Entretanto, no setor público há sérias limitações na apuração do custo de capital, tornando a consideração dos gastos com a utilização dos serviços do fator capital um caso totalmente especial num sistema geral de apuração de custos públicos.

Mas, antes de examinarmos as limitações existentes na apuração do custo de capital, convém explicitar quais são, em linhas gerais, os componentes do custo de capital. Entre os dispêndios que constituem custo de capital temos, por exemplo, os gastos de manutenção de itens de ativo permanente (imóveis, máquinas e equipamentos, veículos etc.), gastos (imputações) de depreciação, gastos com aluguel de imóveis ou outros itens de ativo permanente, gastos com leasing de itens de ativo permanente, gastos com empréstimos (juros de financiamentos e de atrasados) e demais gastos com remunerações derivadas de uso de serviços do fator capital. Esses dispêndios que constituem custo de capital, pela classificação estabelecida pela Lei 4.320/64, são componentes das despesas correntes, quer do subgrupo de despesas de custeio, quer do subgrupo de transferências correntes. Já os gastos com treinamento de mão-de-obra são investimento em capital humano e, portanto, devem ser tratados como investimento no setor público.

Especificamente com relação às limitações à apuração do custo de capital, cumpre notar que os sistemas de informação existentes nesse setor não contemplam uma avaliação adequada de patrimônio. Desse fato resulta que, para itens de ativo permanente (imóveis, veículos, máquinas e equipamentos) em geral, não é possível sua utilização para o cálculo de custos, pois se necessita imputar valores de utilização do patrimônio e de sua depreciação. Somente no caso em que os serviços públicos e/ou as atividades desenvolvidas em determinado nível administrativo sejam produzidos em imóveis alugados (com aluguel, ou com leasing de itens de ativo permanente, como máquinas e veículos), o valor desse aluguel torna explícito o custo de utilização dos serviços desse item e, então, ele pode ser utilizado como custo de fator capital para cômputo de custo. Em imóveis próprios (ou outros itens de ativo permanente), por sua vez, necessita-se imputar os valores de aluguel e de depreciação correspondentes, mas essa informação não existe e, em geral, é difícil e muito dispendiosa a sua obtenção e atualização contínua.

Outro aspecto limitativo importante dos gastos relativos aos serviços do fator capital são os gastos com os juros. O componente de juros mais importante de gastos no setor público, ou seja, os dispêndios de juros com a dívida mobiliária, não é passível de ser considerado na apuração de custos por três razões. Em primeiro lugar, a acumulação de dívida mobiliária (e, portanto, o serviço dela: os juros) está associada à captação de recursos financeiros para viabilizar a produção (oferta) de produtos ou serviços públicos que se deu em algum momento. Os dispêndios com juros da dívida mobiliária do setor público não dizem respeito à oferta corrente de produtos ou serviços e, portanto, não são custos por não corresponderem ao uso corrente do fator capital utilizado na elaboração desses no presente. Em segundo lugar, esses dispêndios de juros sobre a dívida mobiliária não permitem sua vinculação com um produto ou serviço específico. E, finalmente, também não é possível a vinculação dos 
dispêndios de juros sobre a dívida mobiliária com os específicos níveis administrativos do setor público, que foram as fontes geradoras dessa dívida. As limitações apontadas para a consideração dos juros da dívida mobiliária na apuração de custos também se aplicam, em geral, aos empréstimos e financiamentos tomados pelo setor.

Portanto, a consideração dos custos com a utilização dos serviços do fator capital é problemática, implicando que a apuração do custo total (custo variável mais custo fixo) é impraticável com os sistemas de informação atuais $^{15}$, sendo a apuração rotineira do custo direto (custo fixo direto mais custo variável direto), na maioria dos casos, muito difícil. O que parece ser viável e, certamente, com menor grau de ambigüidade, é orientar a apuração rotineira de custos para o conjunto dos custos variáveis (diretos e indiretos), que são representados pelos gastos com pessoal - sendo esse item, de longe, o maior componente de custo no setor público - e gastos com o consumo de materiais, bens e serviços intermediários. Entretanto, toda vez que for possível vincular diretamente um gasto com utilização de serviços do fator capital, como sendo gerado por um determinado produto/serviço ou atividade, então esse custo de capital também deverá ser incorporado na apuração de custos do Governo.

Em suma, o sistema geral de custos que sugerimos para o setor público agrega rotineiramente informações de custo resultantes de gastos com pessoal (ativo) e de gastos com o consumo de insumos intermediários (i.e., consumo de materiais e de bens e serviços intermediários) em determinado período de tempo, isto é, centraliza a apuração de custos nos custos variáveis que, na contabilidade pública, são componentes das despesas correntes de custeio. Mas, toda vez que dispêndios ocorridos com a utilização de serviços do fator capital possam ser diretamente vinculados a determinado produto/ serviço ou atividade do Governo, esses itens de custo de capital também serão computados, em adição aos custos variáveis, na apuração de custos. $\mathrm{Na}$ contabilidade pública, os custos de capital são componentes das despesas correntes de custeio e das despesas de transferência correntes (juros). A apuração de custos que sugerimos será operada, como explicitaremos, em completa integração com os sistemas de informação existentes no Governo, sendo flexível e adaptável a mudança tanto de itens quanto das condições de operacionalização do processo orçamentário.

\section{Sistemas de informação e a metodologia do sistema geral de custos para o setor público}

Ressaltamos anteriormente que, do ponto de vista econômico, custo está intrinsecamente associado à noção de produto ou serviço. Entretanto, do ponto de vista contábil, custo pode ter uma dimensão adicional voltada para aspectos administrativos e gerenciais. De modo que o objeto do custo na contabilidade de empresas constitui-se de qualquer item a que um custo é atribuído, por exemplo, a um departamento ou a uma linha de produtos (MAHER, 2001). Assim, o custo teria, no caso de um departamento, um escopo de gastos nos diversos níveis administrativos devido à realização de um conjunto das atividades da empresa e, no caso de produto, um escopo de gastos para disponibilizar determinado produto no mercado. Portanto, a estruturação do sistema de apuração de custos com base 
nos sistemas de informação está, de modo semelhante, desenhada para subsidiar os dirigentes responsáveis pela gestão pública em pelo menos três tipos de situação:

a) Quando se procura identificar se alguma distribuição de recursos (humanos e materiais) entre unidades ou departamentos não poderia ser melhorada;

b) Quando se procura identificar se a distribuição de recursos entre os produtos e serviços ou entre as funcionais programáticas não poderia ter alguma melhoria; e

c) Quando se auxilia o processo de elaboração do orçamento ao fornecer dados de custo de programas, projetos e atividades e, assim, também subsidiar nas decisões sobre a manutenção ou reforço desses no orçamento.

Os registros das despesas nos sistemas de informação no setor público contemplam a indexação pelo nível administrativo e pela funcional-programática a que se destinam. Assim sendo, essas duas classificações são a base em torno da qual o sistema de custos aqui sugerido se organiza. Nesse sentido, o sistema de apuração de custos pode fornecer informações de custo nas três óticas seguintes:

1) A primeira delas é em nível de estrutura administrativa. Nesse direcionamento, o sistema de custos pode fornecer informações de custo para cada um dos seguintes níveis administrativos: Unidade Orçamentária (UO), Unidade Gestora Executora (UGE) e Unidade Administrativa (UA).

2) A segunda ótica é de que esse sistema também pode fornecer informações de custo em termos de todas as categorias e subcategorias constantes na classificação funcional-programática. O sistema de custos é capaz de informar custos de cada um das várias funções, subfunções, programas, projetos e atividades exercidos no setor público. Nessa segunda ótica, busca-se aproximar o conceito de custo de produto ou de serviços do Governo com alguma das categorias e subcategorias envolvidas na classificação Funcional-Programática. A compatibilidade estreita entre produto ou serviço do Governo com projeto ou atividade, como constante na classificação funcional-programática, pode depender, entretanto, de um aprimoramento no processo de elaboração do orçamento, com uma melhor definição de programas, projetos e atividades.

3) A terceira ótica corresponde a um cruzamento das duas óticas mencionadas, isto é, o sistema pode fornecer informações de custo por funcional-programática em cada nível administrativo e vice-versa. Assim, por exemplo, pode-se saber o custo do ensino médio (uma funcional programática) numa determinada escola (uma UA), em várias escolas (UAs) ou conjuntos de escolas (UGEs), ou, ainda, pode-se saber os custos de cada funcional-programática desempenhada em determinada(s) ou em todas as UAs. Nessa terceira ótica, portanto, poderá ser comparado, em termos de custo, o desempenho de certas UAs na execução de determinada funcional-programática. Por exemplo, poder-se-ia comparar o custo do ensino médio (Funcional Programática) entre as várias escolas (UAs) e, assim, ser capaz de estabelecer um padrão (médio ou de fronteira de eficiência) de custo para essa funcional-programática. A partir desse padrão, por sua vez, poderiam ser estabelecidas metas de redução de custo por escola.

Explicitamos acima que o sistema geral de custos sugerido aqui para o setor público efetua a apuração rotineira de custos baseada nos custos variáveis (diretos e indiretos), sendo estes representados pelos 
gastos com pessoal e pelos gastos com o consumo de materiais, bens e serviços intermediários. Com relação aos custos com a utilização dos serviços do fator trabalho, a situação existente nos registros de informação da despesa com pessoal apresenta, em geral, dois problemas principais, com vistas à estruturação de um sistema de custos:

a) Não há necessariamente uma vinculação fidedigna do funcionário público, como constante no registro de UA na folha de pagamentos, com a UA de efetiva atuação;

b) Não há registro na folha de pagamentos sobre a atuação efetiva do servidor público em termos da funcional-programática para a qual atua.

Esses dois problemas, entretanto, podem ser solucionados por um processo de melhoria ou modernização da folha de pagamentos. Por exemplo, o Governo do Estado de São Paulo desenvolve um Plano de Modernização da Folha de Pagamentos que atinge a administração direta. $\mathrm{Na}$ sua primeira fase de implantação, cada UA alimentará, via web (e, portanto, de modo descentralizado), os dados das freqüências e da funcional-programática dos servidores que efetivamente atuam na UA para o processamento da folha de pagamentos. Assim sendo, com essa modernização na folha de pagamentos as despesas com pessoal da ativa estão indexadas com o nível administrativo (até UA) e com a funcional-programática de efetiva atuação dos servidores públicos. Para efeitos de apuração de custos, após o processamento da folha as informações de despesas de pessoal ativo são carregadas de modo automático em um novo grupo de contas (de custos), na conta corrente do Siafem, segundo um layout predefinido, identificando o tipo de evento, os níveis administrativos (até UA), as categorias de funcional-programática, a natureza da operação e o valor da operação (ou seja, o custo de pessoal). Portanto, a apuração de custos de pessoal em termos de valor pode ser efetuada nas três mencionadas óticas: por nível administrativo, por funcional-programática e pela inter-relação dessas duas classificações. Num sistema de custos baseado em custeio variável também é necessário obter os valores do consumo de materiais e de bens e serviços intermediários nas atividades do setor público. No entanto, em geral os sistemas de informação desse setor apresentam dois problemas principais com relação às despesas com insumos intermediários. Esses problemas impedem de se extrair dos registros das despesas públicas com insumos intermediários o custo devido ao consumo de materiais e de bens e serviços intermediários. Os dois problemas são:

c) Não há vínculo entre a aquisição dos insumos intermediários com os fluxos de consumo efetivo desses, em termos dos níveis administrativos (até UA);

d) Não há vínculo entre a aquisição dos insumos intermediários com os fluxos de consumo efetivo desses, em termos da funcional-programática em que foram utilizados.

Entretanto, mediante um procedimento simples de lançamento de controle no Siafi ou no Siafem, efetuado pelo almoxarifado, esses dois problemas são superados. Evidentemente, parte-se do pressuposto de que as informações sobre o consumo efetivo de materiais e de bens intermediários nos vários níveis administrativos (até UA) e em termos de efetiva funcional-programática de destino podem ser obtidas, no seu melhor grau de fidedignidade, no 
almoxarifado. Essa suposição baseia-se no fato de que é o almoxarifado quem envia esses itens para a UA e a funcional-programática, à medida que esses os demandem efetivamente para uso nas atividades do setor público e, por isso, possui a melhor informação.

O que se requer do almoxarifado, para efeitos da operacionalização do sistema de custos, é um lançamento adicional (de controle) ao que normalmente é efetuado na ocasião do envio dos materiais e bens intermediários. Por exemplo, no caso do Governo do Estado de São Paulo, simultaneamente ao lançamento tradicional, o almoxarifado efetua um lançamento no novo grupo de contas (de custos), na conta corrente do Siafem, mediante uma nova transação de Nota de Lançamento de Consumo. Nesse lançamento adicional o almoxarifado registra os níveis administrativos, as categorias de funcional-programática, a natureza da operação e o valor do consumo de insumos intermediários. Portanto, esse registro permite identificar o valor de consumo dos insumos intermediários, a efetiva UA que utilizou os itens e também qual categoria na classificação funcional-programática utilizou os materiais e bens intermediários. Assim sendo, esse lançamento adicional efetuado pelo almoxarifado, na ocasião do envio dos materiais e bens intermediários, permite o cômputo dos custos de materiais por nível administrativo (até UA) e em termos da classificação funcional-programática, o que viabiliza o cômputo desses custos nas três óticas referidas.

Finalmente, como já esclarecemos, os gastos com utilização dos serviços do fator capital, ou custo de capital, são um caso especial. Eles somente deverão ser considerados para efeitos de apuração de custo quando puderem ser diretamente vinculados a uma funcional-programática e a um determinado nível administrativo.

Em suma, a metodologia de apuração de custos sugerida para o setor público brasileiro, a qual se encontra em implantação no Governo do Estado de São Paulo, é uma estrutura flexível, de baixíssimo custo na operacionalização do sistema de custos e permite a apuração de custos em termos de valor de várias formas, segundo necessidades do gestor público. Os custos podem ser apurados segundo três óticas: por Nível Administrativo, por FuncionalProgramática e pela inter-relação dessas duas categorias. Do ponto de vista contábil, os custos que em geral são rotineiramente apurados são os custos variáveis (pessoal e insumos intermediários), estando seus componentes inseridos no subgrupo de despesas de custeio das despesas correntes. Portanto, essa apuração pode restringir-se aos custos variáveis diretos ou aos custos variáveis totais (diretos e indiretos), evidentemente necessitando-se de definição de critérios de rateio para a alocação dos custos variáveis indiretos. Os custos de capital são considerados na apuração de custos desde que possam ser diretamente vinculados a uma funcional-programática e a um nível administrativo. $\mathrm{O}$ sistema de custos aqui sugerido, ao apurar os custos variáveis (diretos e indiretos) com complementação ocasional de custos de capital, minimiza eventuais problemas devidos à subestimação de custos e contribui, mais do que o simples custeio direto, para o atendimento dos critérios de eficiência operacional e eficiência alocativa no processo orçamentário. Além disso, as informações de custo são obtidas dos sistemas de informação atualmente em uso com um mínimo de adaptações, podendo ser carregadas e geridas em um novo grupo de conta (de custos), conta corrente no próprio Siafi ou no Siafem. 


\section{Considerações finais}

O sistema geral de análise e apuração de custos que moldamos para o setor público brasileiro está baseado no cômputo dos custos variáveis (pessoal e insumos intermediários) com complementação ocasional de custos de capital. As informações para apuração de custos na contabilidade pública são encontradas nas despesas correntes, mais especificamente no subgrupo das despesas de custeio e, eventualmente, na apuração de juros, no subgrupo das transferências correntes. Os custos podem ser apurados segundo três óticas (por nível administrativo, por funcional-programática e pela inter-relação dessas duas categorias), sendo que os custos apurados são em termos de valor. Evidentemente, a escolha do método de custeio deve ser compatível com os sistemas de informação existentes. Mostramos que os sistemas de informação em uso no setor público permitem um método de custeio mais apurado do que simplesmente o custeio direto, isto é, permitem o custeio variável (direto e indireto) com complementação ocasional de custos de capital. Na verdade, sustentamos que o método de custeio direto, proposto por alguns analistas para o setor, é quase impraticável em razão das dificuldades existentes na apuração do custo de capital.
De modo que a apuração de custos públicos sugerida neste artigo minimiza problemas de subestimação de custos e, assim, contribui mais do que as alternativas para o atendimento dos critérios de eficiência operacional e eficiência alocativa no processo orçamentário.

Além disso, a principal qualidade que um sistema de custos deve ter é de ser flexível e, portanto, comportar vários níveis ou formas de análise de custo, além de possuir adaptabilidade a mudanças nas condições e na composição do processo orçamentário. O sistema de custos que elaboramos possui essas qualidades, tem baixo custo de operacionalização e, o que talvez seja sua maior qualidade, funciona plenamente integrado aos sistemas de informação, sendo gerido dentro do próprio Siafi ou do Siafem, em um novo grupo de contas, na sua conta corrente. Assim sendo, o sistema geral de custos explicitado neste artigo possui todas as características desejáveis para um sistema geral de custos que atenda à determinação geral da Lei de Responsabilidade Fiscal, sendo aplicável a todos os níveis executivos do setor público brasileiro, mesmo porque os sistemas de informação geridos pelo Governo do Estado de São Paulo estão presentes nos demais entes da Federação.

(Artigo recebido em dezembro de 2007. Versão final em setembro de 2008).

\section{Notas}

${ }^{1}$ Ver Giacomoni (1992) e Freitas (1999).

${ }^{2}$ Citado por Freitas (1999), página 95.

${ }^{3}$ Ver, por exemplo, Alesina e Perroti (1996).

${ }^{4}$ Para maiores detalhes sobre as reformas do processo orçamentário implementadas no espírito da nova administração do dispêndio público, consultar Schick (1998), Campos e Pradham (1996) e também Kelly e Wanna, (2001). 
${ }^{5}$ Os exemplos mais destacados de países desenvolvidos com reformas do processo orçamentário na ótica da nova administração do dispêndio público são a Nova Zelândia, a Austrália e a Inglaterra.

${ }^{6}$ Mas, evidentemente, a Lei de Responsabilidade Fiscal também altera profundamente a gestão fiscal nas demais esferas da Federação, como veremos a seguir.

${ }^{7}$ Ver também as referências citadas em Catelli et alli (2001), na página 86.

${ }^{8}$ Enquanto no setor privado a motivação da maximização de lucros impulsionou para a obtenção da minimização de custos, com conseqüente necessidade de apuração de custos por sistemas de custos adequados, sendo esses imprescindíveis para própria e correta precificação dos produtos, o mesmo não ocorreu no setor público. Como não há a motivação da maximização do lucro, o desenvolvimento de sistemas de custo adequados ao setor público, embora sejam imprescindíveis à obtenção de eficiência na alocação de recursos e à eficiência operacional, não tiveram o sentido de urgência e o caráter crucial de desenvolvimento como ocorreu no setor privado. Por isso, acreditamos que a apuração de custos no setor público tem tido um desenvolvimento menos adequado do que seria desejável.

${ }^{9}$ Os métodos de custeio são os seguintes: custeio por absorção, o qual se apropria de todos (e somente) os custos de produção, sejam eles fixos ou variáveis; custeio pleno, o qual se apropria de todos os custos de produção e demais despesas, inclusive financeiras, sejam eles diretos ou indiretos, fixos ou variáveis, incorridos na colocação de determinado produto no mercado; custeio por atividade $(\mathrm{ABC})$, apropria todos os custos rastreáveis através de direcionadores a determinado produto; custeio variável, o qual se apropria de apenas os custos variáveis, quer diretos ou indiretos, incorridos na colocação de determinado produto no mercado; e custeio direto, o qual se apropria de apenas os custos diretos, quer fixos ou variáveis, perfeitamente identificados com determinado produto.

${ }^{10} \mathrm{Na}$ página 42 (Alonso, 1999), o autor explicita que o progresso tecnológico e a integração da economia mundial produziram mudanças nas estruturas de produção, nas técnicas de administração de empresas e na contabilidade de custos com: aumento da mobilidade de fatores de produção; aumento relativo da importância do setor de serviços; prevalência dos custos indiretos em relação aos diretos; prevalência dos custos fixos em relação aos variáveis; introdução da competição internacional; e maior instabilidade nos padrões de mercado. Na argumentação de Alonso, essas mudanças limitam e distorcem a metodologia tradicional de custeio na apuração dos custos.

${ }^{11}$ Embora na contabilidade tradicional os gastos com serviços do fator trabalho sejam considerados como "gastos variáveis", isto é, dependem do nível da produção, esse critério é discutível no setor público. A razão disso é que, dado que o servidor público em geral dispõe de estabilidade, os gastos com pessoal são relativamente inflexíveis para baixo. A despeito disso, seguiremos a nomenclatura tradicional e consideraremos, para todos os efeitos, os gastos com pessoal como sendo "gastos variáveis" (ou semivariáveis, como alguns preferem) e não como custos fixos do setor público.

${ }^{12}$ Esse tipo de despesa "variável", que representa custo de fator trabalho e custo de insumos intermediários à Lei 4.320/64, normatiza a sua classificação como sendo componente das despesas correntes, mais especificamente faz parte do subgrupo de despesas de custeio. Ver em Araújo e Arruda (2004), Capítulo 5.

${ }^{13}$ Aqui é preciso fazer um esclarecimento para distinguir entre custo de capital e despesa de capital. Custo de capital são os gastos com a utilização do fator (fixo) capital nas atividades do setor público. Esse gasto, que representa custo de capital, é registrado na contabilidade pública como despesa corrente e se diferencia de despesa de capital, a qual é o outro item de despesa que, conjuntamente com os gastos correntes, compõe o total dos gastos públicos. Na contabilidade pública, as despesas de capital são aquelas realizadas com o propósito de formar ou adquirir ativos reais e subdividem-se em investimentos e inversões financeiras (ARAúJO e ARRUDA, 2004, Cap. 5). 
${ }^{14}$ Ver Araújo e Arruda (2004), Capítulo 5.

${ }^{15}$ É evidente que esse problema deixa de existir se o setor público incorporar novos sistemas de informação que eliminem as imperfeições aqui apontadas com relação à apuração do custo de capital. Uma dessas medidas, por exemplo, seria a incorporação de sistemas adequados de avaliação de patrimônio.

\section{Referências bibliográficas}

Alesina, A. e R. Perotti (1996) - Fiscal Discipline and the Budget Process, American Economic Review Papers and Proceedings 86, p.401-7.

Alonso, Marcos (1999) - Custos no serviço público, Revista do Serviço Público, ano 50, no. 1, Jan-Mar. 1999, p.37-63.

Araújo, I. e D. Arruda (2004) - Contabilidade Pública: da Teoria à Prática, Editora Saraiva, 2004.

Bresser Pereira, L.C. (2000) - A reforma gerencial do Estado de 1995, Revista de Administração Pública, vol.34, no. 4, jul-ago. 2000, p.7-26.

Campos, Ed e S. Pradhan (1996) - Budgetary Institutions and Expenditure Outcomes: Binding Governments to Fiscal Performance, Policy Research Working paper 1646, World Bank, 1996.

Catelli, Armando (1999) - Controladoria: uma abordagem da Gestão Econômica GECON, Editora Atlas, 1999.

Catelli, A., C. Parisi, E.S. Santos e L.B. de Almeida (2001) - Um sistema para a gestão econômica de organizações governamentais empreendedoras, Revista do Serviço Público, ano 52, no 3, Jul-Set. 2001, p.83-100.

Freitas, Carlos Alberto Sampaio (1999) - A implementação do Government Performance and Results na administração pública dos EUA, Revista do Serviço Público, ano 50, no 3, Jul-Set. 1999, p.93-122.

GARCES, A. e J.P. Silveira (2002) - Gestão pública orientada para resultados no Brasil, Revista do Serviço Público, ano 53, no 4, Out-Dez. 2002, p.53-77.

Giacomoni, James (1992) - Orçamento Público, Editora Atlas, 1992.

GiuberTi, Ana Carolina (2005) - Lei de Responsabilidade Fiscal: Efeitos sobre o gasto com pessoal dos municípios brasileiros, in: XXXIII Encontro Nacional de Economia ANPEC, CD-ROM, Anais da ANPEC, 2005.

Kelly, J. e J. Wanna (2001) - A nova gestão pública e as políticas de programação orçamentária do governo, Revista do Serviço Público, ano 52, nº 3, Jul-Set. 2001, p.53-82.

Machado, Nelson (2002) - Sistema de Informação de Custo: Diretrizes para Integração ao Orçamento Público e à Contabilidade Governamental, Tese de Doutorado defendida na Faculdade de Economia, Administração e Contabilidade, Departamento de Contabilidade e Atuária, da Universidade de São Paulo, dezembro de 2002. 
Maher, Michael (2001) - Contabilidade de Custos: Criando Valor para a Administração, Editora Atlas, 2001.

Nascimento, Edson Ronaldo (2004) - Três anos da Lei de Responsabilidade Fiscal, mimeo.

Rezende, Flávio Cunha (1998) - Clinton e a reinvenção do governo federal, Revista do Serviço Público, ano 49, no 1, Jan-Mar 1998, p.93-140.

SHICK, Allen (1998) - A Contemporary Approach to Public Expenditure Management, publicação do World Bank Institute.

Tabellini, G. e A. Alesina (1990) - Voting on the Budget Deficit, American Economic Review, vol.80, n 1, p.37-49, 1990.

Velasco, Andrés (1998) - The common Property Approach to the Political Economy of Fiscal Policy, in F. Sturzenegger and M. Tommasi (editors), The Political Economy Reform, cap. 8, The MIT Press, 1998. 


\section{Resumo - Resumen - Abstract}

O processo orçamentário e a apuração de custos de produtos e serviços no setor público do Brasil

Carlos A. Luque, Hélio N. Cruг, Cicely M. Amaral, Siegfried Bender e Paulo M. dos Santos

O presente artigo aborda a questão da apuração de custos de serviços públicos a partir da perspectiva do processo orçamentário no setor público. Nesse sentido, o objetivo principal do trabalho consiste em explicitar uma sistemática de análise e apuração de custos de serviços públicos que seja adaptada ao processo orçamentário do setor público brasileiro e, assim, contribuir para a obtenção da eficiência alocativa e eficiência operacional. A sistemática de apuração de custos aqui proposta é totalmente compatível com os sistemas gerenciais de informação utilizados pelo Governo e tem baixo custo de operacionalização porque não implica mudanças apreciáveis nos sistemas de informação em uso e na forma de registro das informações na contabilidade pública. Por fim, a sistemática de apuração de custos de serviços públicos proposta atende à Lei de Responsabilidade Fiscal e a complementa quanto à apuração de custos de serviços e produtos do setor público.

Palavras-Chave: Processo Orçamentário, Apuração de Custos, Serviços Públicos.

El processo presupuestario e la apuración de costes de productos y servicios del sector público en Brasil

Carlos A. Luque, Hélio N. Cruz, Cicely M. Amaral, Siegfried Bender y Paulo M. dos Santos

En este artículo abordamos la apuración de los costes de servicios públicos de la perspectiva del proceso presupuestario en el sector público. El objetivo principal dell artículo es explicitar una sistemática de analysis y apuración de costes de servicios públicos adaptada al proceso presupuestario del sector público brasileño, y asi contribuir para la obtención de la eficiencia alocativa e eficiencia operacional del sector público. La propuesta de apuración de costes de servicios públicos efectuada en este artículo es compatible con los sistemas gerenciales de información del Gobierno y tiene un bajo coste de operación, porque no implican alteraciones apreciables en los sistemas de información y en la forma de registro de las informaciones en la contabilidad pública. La sistemática de apuración de los costes de servicios públicos aqui propuesta atiende a la Lei de Responsabilidade Fiscal e la complementa en relación con la apuración de costes de servicios y productos del sector público.

Palabras-Clave: Proceso Presupuestario, Apuración de Costes, Servicios Públicos.

The Public Budget Process and the Estimation of Costs of Products and Services in the Brazilian Public Sector

Carlos A. Luque, Hélio N. Cruv, Cicely M. Amaral, Siegfried Bender and Paulo M. dos Santos

From the point of view of the budget process in the Public Sector this paper deals with public services and products costs. The main objective is to show a model of analysis and estimation of public services costs that is compatible with the budget process in the Brazilian Public Sector, and so contributing to obtain its alocative and operational efficiency. The model of cost estimation showed in this paper is compatible with the managerial information systems of the Government and has a low operational cost, because it does not imply in significant changes of them and of the data registration process in the public accountancy. Finally, the public services costs estimation procedure proposed in this paper attends the Law on Fiscal Responsibility and complements it on the issue of services and products costs estimation in the Public Sector.

Key Words: Public Budget Process, Cost Estimation, Public Services. 
Carlos A. Luque

Professor do Departamento de Economia da FEA-USP.

Contato: cluque@usp.br

Hélio N. Cruz

Professor do Departamento de Economia da FEA-USP.

Contato: hncruz@usp.br

Cicely M. Amaral

Professor Doutor do Departamento de Economia da FEA-USP.

Contato: amaral@usp.br

Siegfried Bender

Professor Doutor do Departamento de Economia da FEA-USP.

Contato:sieg@usp.br

Paulo M. dos Santos

Diretor Técnico da divisão contábil da Secretaria da Fazenda do Estado de São Paulo.

Contato: polmarsantos@yahoo.com.br 


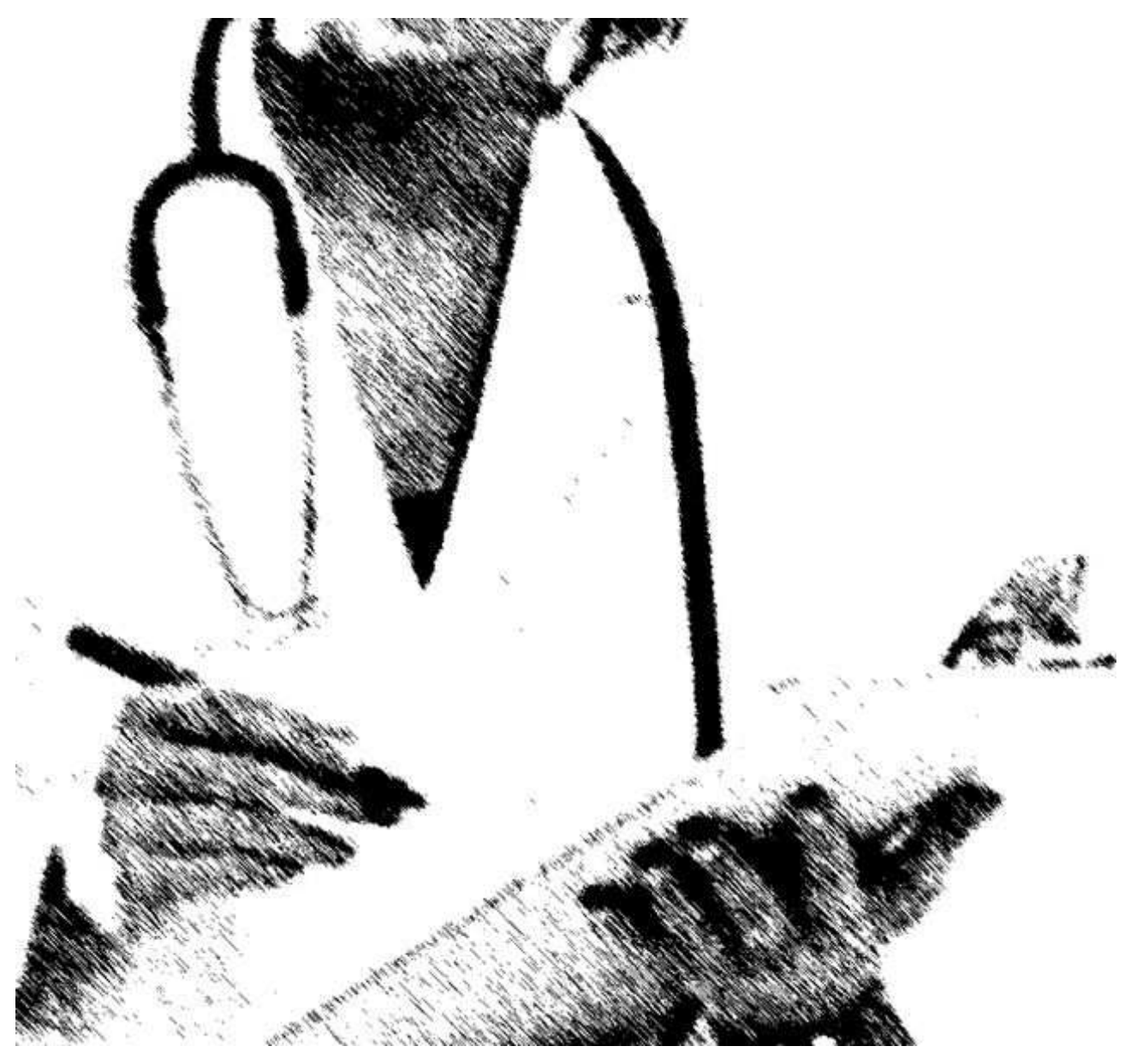

